\title{
Enchanted by science: my study of the endothelial cell
}

\author{
Masaaki Sato \\ Frontier Research Institute for Interdisciplinary Sciences, Tohoku University, 6-3 Aramaki-aoba, Aoba, Sendai 980-8578, Japan
}

(C) Japanese Society of Biorheology 2014

My memory dates back to July 1981, when the fourth International Congress of Biorheology was held at the Jikei University School of Medicine (Chairperson: Dr. Eiichi Fukada). Professor Robert M. Nerem from the United States participated in the congress. At the time I was a lecturer for the biomedical engineering laboratory (Professor Norio Oshima) at the Institute of Basic Medical Sciences, University of Tsukuba. Professor Nerem paid us a visit, affording me an opportunity to convey to him that I wanted to study in his laboratory.

During my education at Kyoto University, I studied the biomechanics of vascular walls under the direction of Dr. Kozaburo Hayashi. Once a week, research meetings were held in the laboratory of Professor Hajime Handa in the Department of Neurosurgery, School of Medicine. I discovered very interesting papers on the involvement of shear stress in atherogenesis. At that time, two controversial hypotheses from blood flow dynamics were circulating in the field of atherogenesis. One was the high shear stress theory by Fry [Circulation, Suppl. IV, 1969] and the second was the low shear stress theory by Caro et al. [Proc. Roy. Soc. London B, 1971]. Many researchers around the world were actively discussing both theories with interest. I was able to learn more about the situation through reading international journals such as Circulation Research, American Journal of Physiology, and Arteriosclerosis (currently Arteriosclerosis, Thrombosis, and Vascular Biology). I felt strongly that I wanted to try my hand at this kind of research and join these researchers. Professor Nerem was an active researcher in this field, and I knew his name from published papers. His background was in aerospace engineering, and he became famous by measuring precisely a distribution of blood flow velocity in the common carotid artery of a horse by using a hot-film anemometer. After that point, he began his research into atherogenesis from the point of view of blood flow dynamics.

When Professor Nerem visited our laboratory at the University of Tsukuba in 1981, I was aware of the above research in atherogenesis. Although he was only 42 years old at the time, I felt very intimidated at that first meeting, because he was already a world-renowned researcher and a large man physically. I did not know when I would have this chance again and did not want to miss this opportunity. I remember telling him with enthusiasm, and in my poor spoken English, of my intention to perform atherogenesis research in his laboratory. I explained my ongoing research on a platelet thrombus model in microvasculature. After a couple of months, I received the good news that he had accepted me into his laboratory. Professor Nerem was the chair of the Department of Mechanical Engineering at the University of Houston. The name Houston was very familiar in Japan because of the launch of the Apollo spacecraft. In those days, communication occurred via regular international mail, not the internet as is commonplace today. Telex (digital communication system using a terminal electric mechanical typewriter) was used in the case of urgent business. I finally joined his laboratory in June, 1983.

I was filled with excitement and great expectations for starting my studies on blood flow dynamics and atherogenesis at the University of Houston. However, I was given the task of measuring the mechanical properties of cultured endothelial cells. In all honesty, I was very disappointed. I was familiar with the name of endothelial cells, but had no experience in cell culture treatments and experiments. Flaherty et al. [Circ. Res., 1972] reported that the nuclei of endothelial cells in the canine aorta were affected by blood flow and changed their morphology. Their report attracted the attention of many researchers. In addition, Dewey et al. [J. Biomech. Eng., 1981] developed a device to apply shear stress to cultured endothelial cells by improving on a coneand-plate-type viscometer and reporting the results. Interesting papers related to cellular response to mechanical stimulation came out in several journals. However, I was still mainly interested in the vessel wall and atherosclerosis, and it took a little time to switch my thoughts to a new research field. According to Professor Nerem, ordered experimental apparatuses such as a glass pipette puller, TV camera and so on were being delivered 6 months later. 
My colleague in research was Dr. Murina J. Levesque, who was responsible for maintaining the cell culture; therefore, I did not need to get involved in that work. Murina was a French Canadian and I my first impression of her was quite negative, because she appeared very inhospitable to me. Although she published papers and was well known as a researcher in the field of cell mechanics, she was also known as an introverted person who did not participate in conferences. She had a reputation as the "phantom researcher." She was very shy, but also a very good person, and happened to live in our neighborhood. We eventually became good friends and research partners while talking and working together in the laboratory. She was a person with an inquiring mind and was in the laboratory from morning until night. I became interested in her experiments and research, and started to make my own experimental apparatus. I ordered the parts from the university workshop and examined the proper testing protocols in published reports. Thus, I began to consider atherogenesis in a different light from what I had imagined before coming to the USA, i.e. the response of endothelial cells to flow-imposed shear stress. At that time, Murina applied shear stress to cultured bovine aortic endothelial cells (BAEC) using a parallel-plate-type flow chamber and precisely observed the actin cytoskeleton in a cell. I had tried to measure the mechanical properties of BAECs using a micropipette method. This method was used mainly for measuring the deformability of the red cell membrane and was not reported for endothelial cells.

I did not have much in the way of experiments to fill my time before the set-up of my experimental apparatus. Since Professor Nerem was so busy, we had a meeting once every two-three weeks and no laboratory meetings. Using this opportunity, I analyzed old experimental data obtained at the University of Tsukuba and wrote manuscript drafts to be published. The drafts were edited and revised by my American friends in the laboratory. When writing English, we Japanese tend to be repetitive and wordy. I learned to write clearly and concisely in English from him. Many English papers were efficiently completed in this way.

However, one problem was proposed by Professor Nerem, which involved the effects of hydrostatic pressure on the functions and morphology of endothelial cells. Those who have learned about material strength in mechanical engineering know that incompressible material does not show any deformation under hydrostatic pressure. A cell is mainly composed of water, an incompressible material, and is not deformed by hydrostatic pressure, provided the water does not move through the cell membrane. I investigated many papers on the effects of hydrostatic pressure on materials in the university library and finally concluded that hydrostatic pressure has no effect on the function and morphology of endothelial cells. My report to Professor Nerem reiterated this conclusion and described a theoretical analysis of the deformation of an oil droplet under shear flow.

However, this was incorrect. I learned that theorizing was not enough, but had to do the experiment to prove it. We had an opportunity to examine the influence of the hydrostatic pressure experimentally in 2002, 10 years after I moved to Tohoku University. Endothelial cells are under three kinds of external forces at the same time in vivo, such as shear stress by blood flow, tension by deformation of the vascular wall and hydrostatic pressure from the blood pressure. From my experience in Houston, I speculated that "there is no influence". However, the result was quite unexpected. In the case of normal endothelial cells, they exist in a monolayer with a so-called cobblestone morphology due to contact inhibition after proliferation. However, endothelial cells become multilayered in two-three cell layers and have a distorted morphology under hydrostatic pressure. We did not know how this happened. It is now known that the expression inhibition of VE-cadherin is important for cell-cell contact.

I studied abroad for one and a half years, repeating such a mistake, and came back again to study at the University of Tsukuba in November, 1984. At this stage, I concentrated all of my energy on the phenomenon of the mechanical response of endothelial cells and the mechanism behind it. I was impressed greatly with this theme and concentrated my main studies on it. However, I had entrusted my cell culture experiments to my colleague, Murina, and was not able to treat them myself. Therefore, I asked the Tsukuba Research Institute of the Eisai company near our university for training. I learned the basics and was able to start a study on cell mechanobiology.

I started my new position as a professor at Tohoku University, Department of Mechatronics and Precision Engineering in 1992, and pursued my own biomechanical studies in earnest. Naturally, I used the theme of "Study of Mechanisms of Cellular Mechanosensing" as the key subject in my laboratory. 